\title{
Advertising Ethics: A Field Study On Turkish Consumers
}

Elif Akagun Ergin, (E-mail: eakagun@cankaya.edu.tr), Çankaya University, Turkey

Handan Ozdemir, (E-mail: h_ozdemir@cankaya.edu.tr), Çankaya University, Turkey

\begin{abstract}
This study examines whether use of deception in ads, cultural stereotyping, sexual stereotyping, and emotional exploitation factors have an influence on the Turkish consumers. Specifically, the aim is to discover whether each of these four factors have any impact on the consumers' recall of the ad and subsequent purchasing decisions. The results of this study should help foreign and domestic advertising agencies and their clients, already existing in or planning to enter the Turkish market, in understanding the Turkish consumers better.
\end{abstract}

\section{INTRODUCTION}

dvertising takes place in a market environment where consumer needs, business interests and
government regulations meet. Advertising is a powerful force and plays a critical social role. It also has high visibility, and pervasiveness. For these reasons, advertising is the subject of criticism and controversy. Much of the controversy over advertising stems from the ways many companies use it as a selling tool and from its impact on society's tastes, values and lifestyles.

Based on the empirical evidence, advertising ethics has been and continues to be a very fertile research topic. Previous research articles examine the ethicality of ads with persuasive appeals (Crisp, 1987; Hyman and Tansey, 1990), exploitive appeals (LaTour and Zahra, 1989, Tansey, Hayman and Brown). Others examine the ethicality of ads with stereotyped actors (Peterson, 1992; Green, 1993), questionable products such as cigarettes, alcoholic beverages (Pomeroy, Castellano, Becker, Johnson, and Brown 1992; Zinkhan et al. 1989), professional services (Bullard and Snizek 1988; Mangold 1987; Stafford 1988). Some other articles focus on the ethicality of targeting ads to children (Strasburger, 2001, Kinsey, 1987) and to other subgroups such as the elderly (Peterson, 1992).

Hyman, Tansey and Clark identify 33 prime topics for those researchers who plan to focus their efforts on advertising ethics. The seven most important topics out of this list include:

- use of deception in ads,

- $\quad$ advertising to children,

- tobacco advertising,

- $\quad$ alcoholic beverage ads,

- $\quad$ negative political advertising,

- $\quad$ racial stereotyping, and

- $\quad$ sexual stereotyping.

For this study, the authors have decided to focus on four areas which consist of use of deception in ads, cultural stereotyping, sexual stereotyping and emotional exploitation.

Turkey is a developing country and has a great potential with a population of 70 million. 52 percent of this total population is under the age of 21 and half of this figure is made up of women. The biggest multinational companies in the world are very much interested in the Turkish market due to its young and dynamic nature. Turkey also has a unique geographic position which enables her to be a bridge between Europe and Asia. Therefore, it is 
possible to observe a mixture of European and Asian values in the society's cultural, social, political, and economic life. Turkish consumers have complex characteristics. In order to succeed in the Turkish market, it is critical for companies to examine the different layers of these consumers and develop strategies that serve them more effectively.

\section{PURPOSE OF THE STUDY}

This study examines whether use of deception in ads, cultural stereotyping, sexual stereotyping, and emotional exploitation factors have any influence on the average Turkish consumer. Specifically, the authors aim to discover whether each of these four factors have an impact on the consumers recall of the ad and subsequent purchasing decision. This study should help foreign and domestic advertising agencies and their clients, already existing in or planning to enter the Turkish market, in understanding the Turkish consumers better. By doing so, they will be more successful in creating ads that are more effective and congruent with Turkish ethical values.

\section{RESEARCH DESIGN AND METHODOLOGY}

This is a field study conducted with 600 male and female Turkish consumers who live in İstanbul, Ankara, and İzmir. These are the three biggest and most cosmopolitan cities of Turkey.

\section{Determining The Sample Size}

The total population in Turkey is extremely large. Due to the limitation of time, money, and other resources, this study focuses on consumers living in İstanbul Ankara and İzmir. These three cities are selected by judgment sampling method. They are the country's most cosmopolitan cities due to their geopolitical situation and the continuous flow of rural migration they receive. Therefore, they represent the national characteristics of Turkish consumers to a great extent.

140 consumers in Ankara, 116 consumers in İzmir and 344 consumers in İstanbul were selected by the ratio sampling method based on the total city populations, yielding a total sample size of 600 consumers.

\section{Method}

The research is a quantitative study based on a descriptive approach. A survey composed of 27 questions, developed by the researchers, has been used to gather data. The variables used in the surveys were collected from similar, previous researches done in this area and some were developed by the observation and intuition of the researchers. The first 4 questions in the survey, deal with demographic issues such as the subjects' age, city of residence and educational status. Questions 9 through 26 are strictly related to the subject matter of determining the influence of the four selected ethical factors on consumers' ad recall and purchasing decision. Prior to conducting the field study, the validity of the survey questions was assessed through a pilot study including 30 subjects.

The surveys were conducted face-to-face in various shopping malls in Ankara, İstanbul and İzmir. After that, data on the survey forms were coded and entered into the computer. The coded data was sorted and analyzed by SPSS program. Chi-square technique was used for this analysis.

The hypotheses of the study were the following:

H0.1: There is no relationship between the significance of the ethicality of the ad and the consumer's age.

H0.2: In the ads where sexual stereotyping is used, there is no relationship between the consumer's recall of the ad and the purchasing decision.

H0.3: In the ads where cultural stereotyping is used, there is no relationship between the consumer's recall of the ad and the purchasing decision.

H0.4: In the ads where correct product information is presented, there is no relationship between the consumer's recall of the ad and the purchasing decision 
H0.5: In the ads where emotional exploitation is used, there is no relationship between the consumer's recall of the ad and the purchasing decision

\section{FINDINGS OF THE RESEARCH}

The findings are presented below with the aid of data gathered from the result of the analysis.

\section{Distribution Of Subjects According To Age Groups}

Table 1 lists the age groups of the subjects who have completed the survey. According to this distribution, 9 percent of the subjects are in 16-20 age group, the 22,3 percent of the subjects are in 21-25 age group, the 13,5 percent of the subjects are in 26-30 age group, 13,3 percent of the subjects are in 31-35 age group, 14,7 percent of the subjects are in 36-40 age group, and finally the 27,2 percent of the subjects are in 41 and older age group.

Table 1

Distribution of Subjects According to the Age Groups

\begin{tabular}{|c||c||c|}
\hline Age Group & Number of the Test Subjects & Percentage Value \\
\hline \hline $\mathbf{1 6 - 2 0}$ & 54 & 9,0 \\
\hline $\mathbf{2 1 - 2 5}$ & 134 & 22,3 \\
\hline $\mathbf{2 6 - 3 0}$ & 81 & 13,5 \\
\hline $\mathbf{3 1 - 3 5}$ & 80 & 13,3 \\
\hline $\mathbf{3 6 - 4 0}$ & 83 & 14,7 \\
\hline $\mathbf{4 1}$ and older & 163 & 27,2 \\
\hline TOTAL & $\mathbf{6 0 0}$ & $\mathbf{1 0 0 , 0}$ \\
\hline
\end{tabular}

\section{Distribution Of Subjects According To Gender}

Table 2 shows the test subjects according to their gender. As depicted in Table 2, 47 percent of the respondents were female and almost 53 percent of the respondents were male consumers.

Table 2

Distribution of Subjects Based on Gender

\begin{tabular}{|c|c|c|}
\hline \multicolumn{1}{|c|}{ Gender } & Number of the Test Subjects & Percentage Value \\
\hline \hline Female & 281 & 46,8 \\
\hline \hline Male & 319 & 53,2 \\
\hline \hline TOTAL & $\mathbf{6 0 0}$ & $\mathbf{1 0 0 , 0}$ \\
\hline
\end{tabular}

\section{Distribution Of Subjects According To The Education Level}

Table 3 shows the test subjects according to their education level. Based on this distribution; 2,8 percent of the test subjects have a primary school degree, 4,7 percent have a secondary school degree, 32,7 percent have a high school degree, 38,5 percent have a university degree, and 21,3 percent have a graduate degree (master's and/or ph.d.) This is a higher educated sample, because this study is carried out in three of the country's biggest cities where the population is mostly urban. 
Table 3

Distribution of Subjects According to the Education Level

\begin{tabular}{|l||c|c||}
\hline Education Level & Number of Test Subjects & Percentage Value \\
\hline \hline Primary School Degree & 17 & 2,8 \\
\hline \hline Secondary School Degree & 28 & 4,7 \\
\hline \hline High School Degree & 196 & 32,7 \\
\hline \hline Üniversity Degree & 231 & 38,5 \\
\hline \hline Graduate Degree & 128 & 21,3 \\
\hline \hline TOTAL & $\mathbf{6 0 0}$ & $\mathbf{1 0 0 , 0}$ \\
\hline
\end{tabular}

\section{Distribution Of Subjects According To The Income Level}

Within the context of the research, average monthly incomes have been divided into four groups. Based on this, 15 percent of the test subjects have an income level below 400 Turkish Liras (YTL), 9,2 percent have 400-799 YTL, 34,3 percent have 800-1,199YTL, 15,3 percent have 1,200 - 1,599 YTL and 26,2 percent have an income level of 1,600 YTL and above.

Table 4

Distribution of Subjects According to the Income Level

\begin{tabular}{||c||c|c||}
\hline Monthly Income Level & Number of Test Subjects & Percentage Value \\
\hline \hline Below 400 TL & 90 & 15,0 \\
\hline $\mathbf{4 0 1 - 7 9 9} \mathbf{~ T L}$ & 55 & 9,2 \\
\hline \hline $\mathbf{8 0 0}-\mathbf{1 , 1 9 9}$ TL & 206 & 34,3 \\
\hline \hline $\mathbf{1 , 2 0 0 - 1 , 5 9 9}$ TL & 92 & 15,3 \\
\hline $\mathbf{1 , 6 0 0}$ and above & 157 & 26,2 \\
\hline TOTAL & $\mathbf{6 0 0}$ & $\mathbf{1 0 0 , 0}$ \\
\hline
\end{tabular}

\section{Distribution Of Subjects According To The Cities They Live In}

Distribution of the test subjects are presented in Table 5 according to the cities where they live. Ratio Sampling Method is used for this distribution. By this method, the city's total population is proportioned to the sample size and the results are listed as; 25,2 percent of the test subjects are living in Ankara, 59,6 percent are living in İzmir and 15,2 percent of the subjects are living in İstanbul.

Table 5

Distribution of Subjects According to the Cities They Live in

\begin{tabular}{|c||c|c||}
\hline Cities & Number of Test Subjects & Percentage Value \\
\hline \hline Ankara & 140 & 25,2 \\
\hline \hline İzmir & 116 & 59,6 \\
\hline \hline İstanbul & 344 & 15,2 \\
\hline TOTAL & $\mathbf{6 0 0}$ & $\mathbf{1 0 0 , 0}$ \\
\hline
\end{tabular}




\section{Distribution Of Subjects Based On Watching/ Listening/ Reading Advertisements}

Table 6 presents the rates of consumers watching TV commercials, listening to radio ads and reading newspaper ads. This analysis provides that 82,5 percent of the respondent consumers watch television commercials while 17,5 percent fail to do so. In addition, 70,2 percent of respondents listen to the radio ads while 76,7 percent of the consumers read newspaper ads.

Table 6

Distribution of Subjects Based on Watching/ Listening/ Reading Advertisements

\begin{tabular}{|c|c|c|c|c|c|c|}
\hline \multirow{2}{*}{$\begin{array}{l}\text { Rate of Watching/ } \\
\text { Listening/ Reading } \\
\text { Advertisements }\end{array}$} & \multicolumn{2}{|c|}{ TV Commercials } & \multicolumn{2}{|c|}{ Radio Ads } & \multicolumn{2}{|c|}{ Newspaper Ads } \\
\hline & $\begin{array}{c}\text { Number of } \\
\text { Test Subjects }\end{array}$ & $\begin{array}{c}\% \\
\text { Value }\end{array}$ & $\begin{array}{c}\text { Number of } \\
\text { Test Subjects }\end{array}$ & $\begin{array}{c}\% \\
\text { Value }\end{array}$ & $\begin{array}{c}\text { Number of } \\
\text { Test Subjects }\end{array}$ & $\begin{array}{c}\% \\
\text { Value }\end{array}$ \\
\hline YES & 495 & 82,5 & 421 & 70,2 & 460 & 76,7 \\
\hline NO & 105 & 17,5 & 179 & 29,8 & 140 & 23,3 \\
\hline TOTAL & 600 & 100,0 & 600 & 100,0 & 600 & 100,0 \\
\hline
\end{tabular}

\section{Evaluation And Distribution Of Most Popular Types Of Ads}

Table 7 lists the most popular types of ads in the order of importance. After examining this order, it is evident that television commercials rank as number 1 with 61,5 percent. Respondents claim that television ads are the most interesting and attention-grabbing types of ads. The second most popular ads are radio ads with a percentage value of 10,8. Magazine ads and newspaper ads fill the third and fourth spots, with 9,5 percent and 3,2 percent respectively.

Table 7

Distribution of Most Popular Types of Ads

\begin{tabular}{|c|c|c|c|c|c|c|c|c|c|c|c|c|c|c|c|c|}
\hline \multirow[b]{2}{*}{ Ad Types } & \multicolumn{16}{|c|}{ Order } \\
\hline & $\overline{11}$ & $\%$ & 2 & $\%$ & 3 & $\%$ & 4 & $\%$ & 5 & $\%$ & 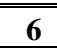 & $\%$ & 7 & $\%$ & $\overline{88}$ & $\%$ \\
\hline Television Ads & 317 & 6 & 34 & 6,6 & 22 & 4,2 & 68 & 13,1 & - & - & 51 & 9,8 & 12 & 2,3 & 14 & 2,7 \\
\hline Newspaper Ads & 16 & 3,1 & 117 & 22,6 & 66 & 12,7 & 88 & 17,0 & 72 & 13,9 & 99 & 19,1 & 31 & 6,0 & 29 & 5,6 \\
\hline Radio Ads & 56 & 10,8 & 131 & 25,3 & 67 & 12,9 & 57 & 11,0 & 37 & 7,1 & 85 & 16,4 & 68 & 13,1 & 17 & 3,3 \\
\hline Magazine Ads & 51 & 9,8 & 54 & 10,4 & 96 & 18,5 & 73 & 14,1 & 65 & 12,5 & 44 & 8,5 & 59 & 11,4 & 76 & 14,7 \\
\hline Billboards & 24 & 4,6 & 13 & 2,5 & 35 & 6,8 & 80 & 15,4 & 70 & 13,5 & 22 & 4,2 & 132 & 25,5 & 142 & 27,4 \\
\hline Brochures & 17 & 3,3 & 108 & 20,8 & 71 & 13,7 & 85 & 16,4 & 64 & 12,4 & 37 & 7,1 & 76 & 14,7 & 60 & 11,6 \\
\hline Banners & 16 & 3,1 & 32 & 6,2 & 49 & 9,5 & 102 & 19,7 & 125 & 24,1 & 73 & 14,1 & 80 & 15,4 & 41 & 7,9 \\
\hline Catalogs & 29 & $\overline{5,6}$ & 62 & $\overline{12,0}$ & 89 & 17,2 & 52 & 10,0 & 78 & 15,1 & 73 & 14,1 & 26 & $\overline{5,0}$ & 109 & 21,0 \\
\hline
\end{tabular}

\section{Evaluation And Distribution Of The Significance Of Ethicality Of Ads}

Question 10 of the survey asked the subjects to indicate whether the ethicality of the ads was a significant (important) factor for them. The results are depicted in the table below. 93,3 percent of the subjects stated that the ethicality of the ads did indeed matter a great deal to them. This result may be due to the higher educated group in the sample. Out of all the respondents, only 6,7 percent stated that the ethicality of the ad was not a significant factor for them. 
Table 8

Distribution of the Subjects According to the Significance of Ethicality of Ads

\begin{tabular}{|l||c|c|}
\hline $\begin{array}{l}\text { Is the ethicality of the ad a significant } \\
\text { (important) factor for you? }\end{array}$ & Number of Test Subjects & Percentage Value \\
\hline \hline Yes & 560 & 93,3 \\
\hline \hline No & 40 & 6,7 \\
\hline \hline Total & $\mathbf{6 0 0}$ & $\mathbf{1 0 0 , 0}$ \\
\hline
\end{tabular}

\section{Distribution Of The Subjects Based On The Impact Of The Ethicality Of The Ad On Ad Recall And Purchasing Decision}

Questions 11 through 20 of the survey asked the respondents whether use of deception in ads, cultural stereotyping, sexual stereotyping, and emotional exploitation factors have any impact on their recall of the ad, and subsequent purchasing decision. Likert Scale was used with these particular questions; "5-Absolutely Agree, 1Absolutely Disagree". 0,5290).

The reliability of this sample is computed by Cochran's Q and is found to be acceptable (alpha Value:

The results are as follows:

- $\quad \mathbf{5 4 , 2}$ of the subjects state that use of sexuality in ads increases the ad's recall, but 29,9 percent do not agree with this. 16 percent of the subjects are undecided about this issue.

- $\quad 67$ percent of the subjects state that use of sexuality in ads increases their decision, to purchase however; 30,7 percent do not agree . 2,3 percent of the subjects are undecided about this issue.

- $\quad 68,5$ percent of the subjects say that use of cultural stereotyping in ads increases the ad's recall, but 27 percent oppose this view. The remaining 4,5 percent of the subjects are undecided.

- $\quad 56$ percent of the respondents say that use of cultural stereotyping in ads does not increase their purchasing decision, but 37,6 percent disagrees. The remaining 6,3 percent of the subjects are undecided about this issue.

- 61 percent of the respondents believe that use of correct/ honest information regarding the products in ads increases the ad's recall, but 27 percent oppose this view. 4,5 percent of the subjects are undecided.

- 62,5 percent of consumers believe that use of correct/ honest information in ads does not increase their purchasing decision, however 25,2 percent disagrees. The remaining 12,3 percent of the subjects are undecided about this issue

- $\quad \mathbf{5 0 , 5}$ percent of the subjects feel that use of emotional exploitation elements in ads increase the ad's recall, but 40,5 percent do not agree with this. 9 percent of the subjects are undecided.

- Interestingly, 65,5 percent of the subjects feel that use of emotional exploitation elements in ads increase their decision to purchase, however 32,4 percent disagrees. The remaining 2,3 percent of the subjects are undecided about this issue

\section{Analyzing The Relationship Between The Significance Of The Ethicality Of The Ad And The Consumer's Age}

After the analysis for these two variables have been completed; (see Table 10) it is observed that the probability value is greater than the $(\alpha=0,05)$ level of significance. In this situation, the H0.1 hypothesis is accepted. Therefore, it is concluded that there is no relationship between the significance of the ethicality of the ad and a consumer's age. 
Table 10

The Relationship Between the Significance of the Ethicality of the Ad and the Consumer's Age

H0.1: There is no relationship between the significance of the ethicality of the ad and the consumer's age

\begin{tabular}{|c||c||c||}
\hline Chi-Square Value & df & p value \\
\hline \hline $8,115^{\text {a }}$ & 5 &, 150 \\
\hline
\end{tabular}

Analyzing The Relationship Between Ad Recall And Purchasing Decision In The Ads Where Sexual Stereotyping Is Used

Table 11 presents the results of this analysis. It is observed that the probability value is smaller than the $(\alpha=0,05)$ level of significance. In this situation, H0.2 hypothesis is rejected. In the ads where sexual stereotyping is used, there is a relationship between the recall of the ad and the consumer's subsequent purchasing decision.

Table 11

The Relationship Between Ad Recall and Purchasing Decision In the Ads Where Sexual Stereotyping is Used

H0.2: In the ads where sexual stereotyping is used, there is no relationship between the consumer's recall of the ad and the purchasing decision.

\begin{tabular}{|c||c|c||}
\hline Chi-Square Value & df & p value \\
\hline \hline $181,435^{\text {a }}$ & 20 &, 000 \\
\hline
\end{tabular}

Analyzing The Relationship Between Ad Recall And Purchasing Decision In The Ads Where Cultural Stereotyping Is Used

As depicted below in Table 12, the probability value is smaller than the $(\alpha=0,05)$ level of significance, therefore, H0.3 hypothesis is rejected. It is concluded that in the ads where cultural stereotyping is used, there is a relationship between the recall of the ad and the consumer's subsequent purchasing decision.

Table 12

The Relationship Between Ad Recall and Purchasing Decision In the Ads Where Cultural Stereotyping is Used

\begin{tabular}{|c|c|c|c|}
\hline \multirow{2}{*}{$\begin{array}{l}\text { H0.3: In the ads where cultural stereotyping is used, there is no } \\
\text { relationship between the consumer's recall of the ad and the } \\
\text { purchasing decision. }\end{array}$} & Chi-Square Value & df & p value \\
\hline & $137,296^{\mathrm{a}}$ & 16 & ,000 \\
\hline
\end{tabular}

\section{Analyzing The Relationship Between Ad Recall And Purchasing Decision In The Ads Where Correct Information About The Product Is Presented}

After the analysis for the two variables is completed, the probability value is observed to be smaller than the $(\alpha=0,05)$ level of significance, therefore, H0.4 hypothesis is rejected. It is concluded that in the ads where correct information about the product is presented, there is a relationship between the recall of the ad and the consumer's subsequent purchasing decision. Deception is the creation of a "false belief" about the product in the mind of a consumer. When an advertisement presents correct information about a product, it leads to a positive impact on the consumer's recall and purchasing decision. 
Table 13

The Relationship Between Ad Recall and Purchasing Decision in the Ads Where Correct Information About the Product is Presented

\begin{tabular}{|c|c|c|c|}
\hline \multirow{2}{*}{$\begin{array}{l}\text { H0.4: In the ads where correct product information is } \\
\text { presented, there is no relationship between the consumer's } \\
\text { recall of the ad and the purchasing decision. }\end{array}$} & Chi-Square Value & df & p value \\
\hline & $166,860^{\mathrm{a}}$ & 16 & ,000 \\
\hline
\end{tabular}

\section{Analyzing The Relationship Between Ad Recall And Purchasing Decision In The Ads Where Emotional Exploitation Is Used}

Analysis of these two particular variables indicate that the probability value is smaller than the $(\alpha=0,05)$ level of significance, thus $\mathbf{H 0 . 5}$ is rejected. It is observed that in the ads where emotional exploitation is used, there is a relationship between the recall of the ad and the consumer's subsequent purchasing decision.

Table 14

The Relationship Between Ad Recall and Purchasing Decision In the Ads Where Emotional Exploitation is Used

\begin{tabular}{|l|c||c||c||}
\hline H0.5: In the ads where emotional exploitation is used, there & Chi-Square Value & df & p value \\
\cline { 5 - 5 } $\begin{array}{l}\text { is no relationship between the consumer's recall of the ad } \\
\text { and the purchasing decision. }\end{array}$ & $112,009^{\mathrm{a}}$ & 16 &, 000 \\
\hline
\end{tabular}

\section{CONCLUSION}

Advertising is accused of encouraging materialism and consumption, of stereotyping, of influencing us to purchase products for which we have no need, of taking advantage of children, and even of manipulating our behavior. The purpose of this paper was to determine if the use of deception in ads, cultural stereotyping, sexual stereotyping and emotional exploitation factors influence the average Turkish consumer. Specifically, the focus was to see if these factors had any impact on the consumers recall of the ad and subsequent purchasing decision. The reason behind this examination was to better understand the complex ethical values of typical Turkish consumers and assist agencies in developing advertisements that target them more efficiently.

Some of the results of this study were quite unexpected. The fact that there is no evident relationship between a consumer's age and the significance of the ethicality of the ad was not expected. In the ads where sexual stereotyping is used, there is a relationship between the recall of the ad and the consumer's subsequent purchasing decision. Similar relationships are also evident in ads that use cultural stereotyping and emotional exploitation. Consumers also tend to remember the ad and get motivated to purchase products/services when they feel that the information in the ad is truthful and not deceptive.

In addition, 71 percent of the consumers feel that the use of sexuality in commercials have an impact on the society's ethical values. 45,8 percent believe that use of children in ads and advertising directly to children is not ethical. 53,3 percent state that tobacco advertising encourages smoking and therefore has a negative effect on society.

Respondent consumers listed the ads for banks, shampoos, newspapers, cars and cleaning products as those with the most deceptive, untruthful information. The most unethical ads are listed as those of Vichy skin care product ads, Jagler perfumes, O.K. condoms, Always tampons and Clairol Herbal Essences shampoos. 


\section{LIMITATIONS OF THE STUDY}

This research is limited in two ways. First, due to limited resources, the authors only sampled those consumers living in the three biggest, most cosmopolitan cities in Turkey. Even though these cities represent the national characteristics of Turkish consumers to a great extent, the results may reveal different issues if this particular study is conducted in more rural areas. Second, this study focused only on four factors (use of deception in ads, cultural stereotyping, sexual stereotyping and emotional exploitation factors) in attempting to determine whether they have an influence on Turkish consumers. In a future study, more factors could be examined in different regions of the country with a broader perspective.

\section{REFERENCES}

1. Carrigan, M. and Szmigin, I. The Ethical Advertising Covenant: Regulating Ageism in UK Advertising International Journal of Advertising, Vol: 19, 2000.

2. Crisp, Roger. Persuasive Advertising, Autonomy and the Creation of Desire, Journal of Business Ethics, July 1987, pp. 413-418.

3. Cunningham, Peggy H. Ethics of Advertising in the Advertising Business John Phillip Jones, ed., Thousand Oaks, CA: Sage, pp. 499-513.

4. Drumwright, Minette E. and Murphy, Patrick E. How Advertising Practitioners View Ethics: Moral Muteness, Moral Myopia and Moral Imagination Journal of Advertising, Summer 2004.

5. Ergün, Mustafa, Bilimsel Araştırmalarda Bilgisayarla İstatistik Uygulamaları- SPSS For Windows Ocak Yayınları, 1995.

6. Hyman, M., Tansey, R. and Clark, J. Research on Advertising Ethics: Past, Present and Future Journal of Advertising, Vol: 23, no: 3, September, 1994.

7. Kinsey, Joanna. The Use of Children in Advertising and the Impact of Advertising Aimed at Children International Journal of Advertising, February 1987, pp.169-175.

8. Latour, Michael S. Ethical Judgements of Sexual Appeals in Print Advertising Journal of Advertising, Vol: 23, September 1994.

9. LaTour, Michael S. and Shaker, Zahra. Fear Appeals as Advertising Strategy: Should They Be Used?, Journal of Consumer Marketing, Spring 1989, pp.61-70.

10. Peterson, Robin T. The Depiction of Senior Citizens in Magazine Advertisements: A Content Analysis Journal of Business Ethics, September 1992, pp.701-706.

11. Schudson, Michael,. Advertising, The Uneasy Persuasion: Its Dubious Impact on American Society Harper Collins Publishers, NY, 1994.

12. Strasburger, Victor C., Children and TV Advertising: Nowhere to run, nowhere to hide. Journal of Developmental \& Behavioral Pediatrics, Vol. 22, June 2001.

13. Toscani, Oliviero, (Çev: N. Önol), Reklam Bize Sırıtan Bir Leştir AD Yayıncılık, İstanbul, 1996.

14. Treise, D., Weigold, M., Conna, J. and Darrison, H. Ethics in Advertising: Ideological Correlates of Consumer Perceptions. Journal of Advertising, Vol:23, no:3, September, 1994.

15. Zinkhan, George., Advertising Ethics: Emerging Method and Trends Journal of Advertising, Vol: 23, no: 3, September, 1994. 


\section{NOTES}

